\title{
A teoria da escolha pública e as reformas do Estado: uma crítica habermasiana
}

\author{
Christina W. Andrews
}

\section{Resumo}

Neste artigo é apresentada uma análise crítica da teoria da Escolha Pública sob a ótica da teoria social de Jürgen Habermas. Essa análise se justifica pelos pontos de convergência entre as duas teorias, ainda que a partir de perspectivas opostas. Enquanto a teoria da Escolha Pública concebe a política como uma relação de troca entre Estado e eleitores, a teoria crítica habermasiana considera que é justamente esse aspecto da política de massas que deve ser superado pela ação comunicativa de cidadãos participantes. Procura-se demonstrar ao longo do texto que o impasse teórico da Escolha Pública - de um lado, como postula o "Teorema da Possibilidade Geral" de Kenneth Arrow, a impossibilidade de uma função-utilidade coletiva e de outro, a ambição normativa de fornecer parâmetros de eficiência para o fornecimento de bens públicos - reside, fundamentalmente, no pressuposto do individualismo metodológico.

A teoria da Escolha Pública pode ser considerada um fenômeno da Ciência Política. Nenhuma outra teoria política teve tanta influência na prática de governos no século $\mathrm{XX}$ do que ela: foi o fundamento teórico da "onda" neoliberal de reformas do Estado que atingiu boa parte dos países ocidentais e também das "novas democracias" do Leste europeu; foi a teoria que reafirmou em nossa época uma ambição iniciada por Hobbes, ou seja, de fazer da política uma ciência positiva, rompendo, assim, com a tradição da política clássica, fundamentada 
na phrônesis, a "compreensão prudente da situação". ${ }^{1}$ Não é por acaso, portanto, que foi na Economia - a mais "positiva" das ciências sociais - que a teoria da Escolha Pública foi buscar os seus pressupostos, métodos e modelos. A tradição hobbesiana, que atinge seu apogeu na teoria da Escolha Pública, porém, pagou o preço a para a atribuição do status de "ciência" à investigação dos fenômenos políticos com dissociação entre teoria e prática. Desde então, a "velha" e a "nova" gerações de teóricos críticos se empenharam em reconciliar essas duas dimensões da política.

Curiosamente, Jürgen Habermas, que dedicou boa parte de seus escritos à crítica da abordagem tecnicista nas ciências sociais, não faz referência à Escolha Pública ao apresentar a sua teoria social crítica, nos dois volumes de The Theory of Communicative Action. ${ }^{2}$ No entanto, há vários pontos de contato entre as duas teorias, ainda que suas perspectivas sejam opostas. A teoria da Escolha Pública está fundamentada nos pressupostos do auto-interesse e do individualismo metodológico, aos quais corresponde, como sua referência básica, a razão instrumental. Como procurarei mostrar adiante, essa concepção de racionalidade (e ação) impõe severas limitações à consistência teórica da Escolha Pública. Por sua vez, a teoria social crítica de Habermas ficou conhecida pela introdução de um conceito de racionalidade e ação abrangentes. Além da ação racional com relação a fins, tipificada na obra de Weber, Habermas introduz o conceito de ação comunicativa, definida como "[...] o tipo de interação na qual todos os participantes harmonizam seus planos individuais de ação uns com os outros e assim buscam seus propósitos elocucionais sem restrições [...]". ${ }^{3}$ Essa orientação contrasta com aquela das ações estratégica e instrumental, na qual atores sociais buscam a realização de seus objetivos independentemente de um entendimento mútuo prévio; nesse caso, a orientação dos atores está voltada para o sucesso. É importante ressaltar que, na concepção de Habermas, só a ação estratégica é considerada uma ação social, uma vez que nesse caso a ação de outros indivíduos é

1 Habermas, J. "The Classical Doctrine of Politics in Relation to Social Philosophy". In: Theory and Practice Boston: Beacon Press, 1973.

2 Idem. The Theory of Communicative Action, v. 1 e 2 Boston: Beacon Press, 1984, 1987. Doravante refereida como TCA.

3 Ibid., v. 1., p. 294. 
levada em consideração pelos ator que busca a realização de seus objetivos. A ação instrumental não é considerada uma ação social, pois está restrita às intenções do indivíduo. $\mathrm{O}$ individualismo metodológico - um dos pressupostos fundamentais da Economia clássica e neoclássica - só concebe esse último tipo de ação. A teoria da Escolha Pública, ao assumir também esse pressuposto, mas agora no campo da política, acaba se enredando em dificuldades teóricas que, a meu ver, são insuperáveis, dada às restrições impostas pela adoção da ação instrumental.

Há ainda outro ponto de contato entre a teoria social crítica habermasiana e a teoria da Escolha Pública: trata-se da tese sobre a reificação de relações sociais e a emergência de patologias sociais. Em TCA, Habermas sustenta que o mundo-da-vida - com seus três componentes estruturais: cultura, sociedade e personalidade - só pode se reproduzir por meio da apresentação, crítica e deliberação de reivindicações de validade, apresentadas por participantes de um discurso sustentado por meio da linguagem comum. Nas sociedades de welfare, esse processo estaria sendo bloqueado pela interferência do sistema administrativo - isto é, do Estado - devido à imposição ao mundo-davida uma interação "deslingüistificada", na qual relações sociais são reificadas pela introdução de abstrações compatíveis com a razão funcionalista dos sistemas. $\mathrm{Na}$ interação com o sistema adminitrativo, as políticas massificadas do welfare state reduzem as interações sociais às abstrações de "cliente do Estado" e "eleitor", reduzindo a formação da vontade política a relações de troca em um "mercado político". ${ }^{4}$ Uma vez que a razão comunicativa é substituída pela razão funcionalista, a reprodução do mundo-da-vida é bloqueada, resultando nas patologias sociais. Em outras palavras, Habermas sustenta que o sistema administrativo só pode estabelecer uma relação com o mundo-da-vida por meio de abstrações que impõem relações de troca, similares àquelas observadas no sistema econômico. Assim como acontece na transformação da força de trabalho em mercadoria, as trocas entre o sistema administrativo e mundo-da-vida também impõem reificações das relações sociais. Ora, nisso consiste justamente a concepção da teoria da Escolha Pública: nessa teoria, as relações entre Estado e sociedade são interpretadas como trocas no "mercado político" e os atores sociais assu-

4 Ibid, v. 2, p. 319-31. 
mem o comportamento pressuposto pelos modelos econômicos neoclássicos, ou seja, a busca pela maximização da função-utilidade. Portanto, o que para Habermas seria a causa das patologias sociais, para a teoria da Escolha Pública é o princípio para a compreensão da vida política. Para superar a reificação das relações sociais impostas pela razão funcionalista, Habermas sugere a preservação de condições que garantam a prática da ação comunicativa. A teoria da Escolha Pública, porém, não pode reconhecer seus princípios como abstrações potencialmente danosas. Suas prescrições, portanto, limitam-se ao alcance imposto por seus pressupostos: o Estado deve ser reduzido ao "mínimo" e as políticas públicas devem adotar "estímulos de mercado".

Nas próximas seções, vermos como a teoria da Escolha Pública acaba enredada em dificuldades teóricas resultantes de seus pressupostos básicos. Para essa discussão, tomarei como principal referência os argumentos de James Buchanan, certamente o mais influente entre os autores vinculados à teoria da Escolha Pública. Finalmente, na última seção, faço uma breve análise da influência dessa teoria em programas de reforma do Estado implementados nos anos 80 e 90.

\section{Os problemas teóricos da escolha pública}

A própria definição da teoria da Escolha Pública encontrada na literatura especializada não deixa dúvidas quanto à origem de seus fundamentos teóricos:

A Escolha Pública pode ser definida como o estudo econômico de decisões extra-mercado no processo de tomada de decisão ou, simplesmente, como a aplicação da economia à Ciência Política. O postulado básico da Escolha Pública, assim como para a economia, é a do homem como um maximizador de utilidade, egoísta e racional. ${ }^{5}$

Na definição apresentada acima, a Escolha Pública seria a teoria das escolhas extra-mercado. Essa afirmação pode levar a alguns malentendidos. Muitos comentaristas da teoria têm afirmado que uma das

5 Mueller, D. C. "Public Choice: A Survey". In: Buchanan, J. M. \& Tollison, R. D. eds. The Theory of Public Choice II, Ann Arbor: University of Michigan Press, 1984. 
principais características da Escolha Pública é a transferência do princípio de mercado para a política. Assim, as escolhas mencionadas na definição não seriam propriamente extra-mercado, mas sim escolhas em um outro tipo de mercado. Lars Udhen considera que os três pressupostos constitutivos da Escolha Pública são: "(1) o auto-interesse, (2) a troca e (3) o individualismo". ${ }^{6}$ Os economistas da public choice tomam o princípio do mercado como um pressuposto universal $e$, por isso, referem-se às interações políticas basicamente como trocas entre eleitores e governantes. Habermas, como vimos acima, considera esse tipo de interação uma abstração com potencial para induzir a emergência de patologias sociais. É preciso lembrar aqui que Habermas também considera a razão funcionalista um tipo especial de racionalidade, que se diferencia da racionalidade teleológica (estratégica ou instrumental) dos atores sociais. No caso da razão funcionalista já não temos mais atores capazes de uma ação consciente, mas apenas a ação de um sistema que age "pelas costas" deles. Em outras palavras, a razão funcionalista dos sistemas sociais impõe uma dinâmica de interação aos atores sociais que é independente da vontade individual de cada um. A seguir, veremos que a teoria da Escolha Pública também pressupõe a existência de um sistema cuja dinâmica produz resultados que não são necessariamente desejados pelos atores. Isso remete à idéia de externalidade, que constitui o ponto de partida da public choice.

A teoria parte inicialmente do foco no processo de escolhas públicas, ou seja, nas escolhas que afetam a comunidade política como um todo. Assim é que a teoria da Escolha Pública preocupou-se em responder à questão: Qual a conseqüência de escolhas que são "públicas" uma vez que são orientadas pelo princípio de maximização de funções de utilidade individuais?. James Buchanan responde a essa questão com uma crítica dirigida aos economistas da teoria do bem-estar, que, ao apregoarem a interferência do Estado para corrigir as falhas de mercado, teriam sido incapazes de notar que o indivíduo que tem um comportamento racional e auto-interessado no mercado é "a mesma pessoa que faz [...] escolhas coletivas ou públicas por toda a comunidade". ${ }^{7} \mathrm{Bu}-$

6 UdEHn, Lars The Limits of Public Choice: A Sociological Critique of the Economic Theory of Politics. New York: Routledge, 1996, p. 11.

7 Buchanan, J. M. "Toward Analysis of Closed Behavioral Systems". In: Buchanan, J. M e Toluson, R. D. eds. Theory of Public Choice: Political Applications of Economics. Ann Harbor: University of Michigan Press, 1972, p. 12. 
chanan acha que é uma contradição considerar que o comportamento desse indivíduo no mercado possa ser essencialmente diferente daquele que acontece em qualquer outro modo de interação social. "O pressuposto implícito [dos economistas do welfare]" - afirma Buchanan "tem sido que uma outra pessoa, alguém diferente do participante no mercado, estabelece as normas para a ordem coletiva". ${ }^{8}$ Para Buchanan, portanto, o comportamento auto-interessado tem status universal: todo e qualquer comportamento social é explicado a partir da premissa do Homo ceconomicus. E é a partir desse "princípio universal" que ele descreve o processo da oferta de bens coletivos. Como a teoria econômica já havia demonstrado, comportamentos individuais podem gerar externalidades, ou seja, conseqüências positivas ou negativas para a comunidade como um todo. As externalidades negativas - poluição, desemprego, monopólios, etc. - são consideradas "falhas de mercado" $e$, segundo os economistas do welfare, deveriam ser corrigidas pela ação de agentes governamentais. Ora - diz Buchanan -, se as intervenções do Estado visando corrigir falhas de mercado afetam o contexto no qual se encontram outros indivíduos, então temos aqui também uma externalidade, mas dessa vez gerada pela ação dos agentes governamentais. Portanto, a ação governamental não pode neutralizar uma externalidade sem gerar outra. ${ }^{9}$ Como se trata da ação de agentes no governo, o resultado dessa externalidade é representado pelo fato de que o decision maker apropriar-se-á de uma parcela maior dos benefícios da atividade pública do que sua contribuição para financiar os custos da intervenção. "No cálculo dos indivíduos efetivamente fazendo a decisão coletiva final, benefícios marginais privados tenderão a exceder os benefícios sociais marginais e/ou os custos marginais privados tenderão a ficar abaixo dos custos marginais sociais". ${ }^{10}$ Temos aqui, portanto, a síntese do argumento que viria a ser difundido sob a denominação de rent-seeking. ${ }^{11}$

8 Ibid., p. 12-3.

9 Buchanan, J. M. "Politics, Policy, and the Pigovian Margins". In: Theory of Public Choice.

10 Ibid., p. 174.

11 Segundo G. Tullock, o termo rent-seeking "foi inventado em 1974 por Anne Krueger em um artigo publicado no American Economic Review". Ver G. Tullock, Rentseeking (Aldershot: Edward Elgar/The Locke Institute, 1993), p. 19. 
Buchanan limitou-se a apontar as limitações da intervenção do Estado, e por isso ficou conhecido, ao lado de Milton Friedman, como um dos principais teóricos do Estado "mínimo". Outros teóricos da public choice, entretanto, não se limitaram à crítica da intervenção do Estado e tentaram encontrar uma saída para o problema da escolha pública. O problema que esses autores se impuseram foi explicar como as preferências coletivas poderiam ser expressas por meio de funções utilidade individuais. Uma resposta a essa questão foi apresentada no conhecido Teorema da Possibilidade Geral (mais conhecido como "Teorema da Impossibilidade"), de Kenneth Arrow, no livro considerado como um dos precursores da teoria da Escolha Pública:

Se excluirmos a possibilidade de comparações interpessoais de utilidade, então os únicos métodos para passar de gostos individuais a preferências sociais que seriam satisfatórias e que seriam definidas para uma ampla abrangência de ordenamentos individuais seriam ou impostas ou ditatoriais. ${ }^{12}$

Em síntese, não seria possível chegar-se a uma função utilidade capaz de expressar a vontade coletiva de todos os membros de uma comunidade política a partir de funções utilidade individuais, pois há uma incompatibilidade lógica no ordenamento de preferências, e qualquer decisão coletiva teria que ser imposta de cima para baixo. Apesar de ter sido formulado em 1951, esse paradoxo continuava a desafiar os teóricos da public choice décadas depois. ${ }^{13}$

As implicações do paradoxo de Arrow para as teorias de democracia e legitimidade não são difíceis de deduzir. O modelo básico de democracia nos modelos de Escolha Pública é o do dilema do prisioneiro: embora a ação mais vantajosa para todos seja a cooperação, não existem incentivos "racionais" para tal, sendo que o resultado conjunto das ações individuais é socialmente pior para todos os envolvidos. Enquanto as trocas de bens privados podem ser satisfatoriamente resolvidas por meio da ação egoísta dos envolvidos, o mesmo não é possível para as trocas envolvendo bens públicos. Uma vez que não se

12 Arrow, K. J. Social Choice and Individual Values (New Haven: Yale University Press, 1963), p. 59.

13 Ver Mueller, D. C. op. cit. e Elster, J. \& Hylland, A. "Introduction”. In: Foundations of Social Choice. Cambridge University Press. 
pode excluir ninguém do consumo de um bem público, o problema é como o oferecer, uma vez que o comportamento "racional" é o do free rider, isto é, esperar que outros forneçam o bem público, em vez de colaborar para seu provimento. Os teóricos da public choice reconhecem que as transações no setor privado dependem do provimento de bens públicos, em especial de um sistema judicial que aplique sanções, pois o roubo e o não-cumprimento de contratos também são considerados comportamentos do free rider. Como bens públicos são inevitáveis, o dilema do prisioneiro também é. "Cada indivíduo estaria em melhor condição se todos contribuíssem para a provisão do bem público do que se ninguém o fizesse, e cada um estaria ainda melhor se ele individualmente não pagasse pelo bem". ${ }^{14}$ Assim, seria preciso desenvolver regras de interação social que viessem a resultar em soluções cooperativas:

Os fundamentos teóricos da Escolha Pública, tal como representados pelo dilema do prisioneiro, $e$ as diferentes possibilidades para se chegar a uma solução cooperativa a esse jogo têm importantes implicações para a seleção de um conjunto de regras democráticas por uma comunidade $[\ldots] .^{15}$

O problema continua sendo, portanto, como chegar a essas regras democráticas mantendo o auto-interesse e o individualismo como pressupostos. Os teóricos da public choice logo chegaram à conclusão de que, se o provimento do bem público é do interesse de todos, então a regra democrática geral seria o "consentimento unânime". Cabe lembrar que essa unanimidade é expressa como uma forma de convergência das funções utilidade de cada cidadão, mas a revelação dessa função de utilidade social encontra barreiras intransponíveis. Para começar, as preferências individuais pelo bem público não são facilmente reveladas, diferentemente do caso dos bens privados, cujas preferências podem ser reveladas pelos preços de mercado. Além disso, nem todos os indivíduos revelarão o mesmo grau de preferência pelo bem público. Diversos modelos tentaram resolver o problema da revelação das preferências por bens públicos substituindo "preço" por "votos". ${ }^{16}$ Mas, nesse caso, seria necessário adotar o pressuposto de que o eleitor sabe

14 Mueller, D. C. op. cit., p. 25.

15 Ibid., p. 27.

16 Ibid., p. 27-9. 
exatamente o valor dos impostos a ser aplicado pelos partidos políticos em disputa eleitoral, para cada "quantidade" dos milhares de bens públicos a serem fornecidos, o que os próprios teóricos da Escolha Pública consideram inviável:

A perda em tempo pelos membros da comunidade para descobrir um conjunto de parcelas de impostos que seja um Ótimo de Pareto pode superar os ganhos para aqueles que são protegidos do pagamento de uma parcela de imposto superior aos benefícios obtidos do bem público. [...] Uma segunda objeção à regra da unanimidade é que ela encorajaria o comportamento estratégico [...]. Se $A$ sabe a parcela máxima de impostos que $B$ assumirá em vez de ficar sem o bem público, $A$ pode forçar $B$ até o ponto $C$ da curva de contato, votando contra todas as parcelas de impostos superiores a $Y$. Todos os ganhos do provimento do bem público então pertenceriam a $A$. Se $B$ se comporta da mesma maneira, o resultado final dependerá da força de barganha dos dois indivíduos. [...] A barganha também pode adiar a realização do acordo, uma vez que cada jogador tem que "testar" a disposição do outro para fazer concessões. ${ }^{17}$

A busca por um modelo matemático capaz de antecipar o resultado de inter-relações políticas, que seria expresso em termos de uma função de utilidade social para todos os possíveis bens públicos, fracassou em termos substantivos. Sua contribuição parece ter sido limitada ao campo de estudos da matemática, sem ter avançado na elaboração de uma teoria política. Essa conclusão é corroborada por Jon Elster e Aanund Hylland, dois destacados expoentes da social choice, ${ }^{18}$ que concluíram que o campo de estudos da escolha racional já teria se esvaziado no formalismo matemático:

Como John von Newmann disse uma vez, a matemática que não tem contato com as ciências físicas tende a se tornar barro$c a$, um termo usado em contraste com o estilo clássico de pensamento que é constantemente revitalizado pelo contato com as

17 Ibid., p. 29.

18 Segundo Fábio Wanderley Reis, o termo social choice theory corresponde à teoria da Escolha Pública normativa. O termo rational choice seria uma designação mais ampla da Escolha Pública. Ver ReIs, F. W. "Apresentação". In: Downs, A. Uma teoria Econômica da Democracia. São Paulo: Edusp, 1999, p. 11-20. 
ciências empíricas. [...] Hoje, a teoria da social choice pode estar alcançando o estágio barroco. Inovações estão desaparecendo, enquanto que pequenos ornamentos estão aumentando. $\mathrm{O}$ formalismo alcançou a prioridade, como naquilo a que Ragnar Frisch costumava se referir como "playomerics". De um meio, o modelamento formal está se tornando um fim em si mesmo. ${ }^{19}$

Ao avançar na questão da alocação dos bens públicos, mantendo o pressuposto de uma racionalidade instrumental egoísta, a Escolha Pública criou um problema para si mesma; mas, ao mesmo tempo, apontou para uma questão subjacente da maior importância: a formação da vontade coletiva. Para os teóricos da Escolha Pública, a busca pela função de utilidade social - considerada a única maneira válida de se falar de uma "vontade coletiva" - tornou-se uma jornada em busca do "santo Graal". Não deixa de ser curioso notar que os teóricos da Escolha Pública tenham chegado à conclusão, ainda que indiretamente, de que a formação vontade coletiva - uma questão aparentemente restrita aos modelos da pólis aritotélica do republicanismo civil permanece como um aspecto fundamental da política. No entanto, ao reconhecer a necessidade de escolhas coletivas strictu sensu, a teoria da Escolha Pública impôs-se um fardo, pois trata-se de um elemento teórico que entra em conflito com os pressupostos do individualismo metodológico e da razão instrumental.

Outro aspecto da Escolha Pública relevante para a nossa discussão refere-se ao caráter positivo ou normativo da teoria, uma vez que trata da questão dos valores coletivos. Dennis Mueller, que escreve a partir da perspectiva da public choice, vê a distinção entre uma e outra abordagem nos seguintes termos:

Algumas decisóes coletivas podem beneficiar todos os indivíduos envolvidos; outras decisões beneficiam uns e prejudicam outros. Essa duas categorias correspondem à distinção familiar entre movimentos [a partir de] fora da fronteira de Pareto para pontos nela e movimentos ao longo da fronteira ou [, em outros termos,] entre alocação e distribuição. A Escolha Pública positiva, como a economia positiva, é mais pertinente para as decisões do primeiro grupo; teorias normativas do bem-estar para

19 Elster, J. \& Hylland, A. (eds.) Foundations of Social Choice Theory. Cambridge University Press, p. 2. 
as decisões pertinentes ao segundo grupo.[...] Se a teoria normativa estuda os processos para revelar os valores coletivamente adotados em relação a comparações interpessoais de utilidade, a Escolha Pública positiva estuda processos para revelar comparações intrapessoais de utilidade. ${ }^{20}$

Mueller observa que o teórico positivo inicia suas investigações a partir do indivíduo; por isso assume os valores coletivos como dados do contexto e considera que "favorecem a manutenção das regras existentes na ausência de claras preferências por uma mudança". O teórico normativo, por sua vez, "procura definir as regras a serem incorporadas a uma nova constituição ideal (talvez nova) e não vê razão para dar prioridade às regras anteriores" ${ }^{21}$ Mas a Escolha Pública como um todo mantém o princípio do individualismo metodológico e por isso sua vertente normativa se vê em apuros. Como justificar normas de interação social universalmente aceitas por meio da racionalidade instrumental?

Para examinar em mais detalhes a abordagem normativa da Escolha Pública, tomarei como referência os argumentos de Buchanan em The Limits of Liberty. ${ }^{22}$ Nesse pequeno livro, a relação entre a teoria positiva e normativa está particularmente evidente. O texto é também um exemplo das dificuldades - insuperáveis, a meu ver - em fundamentar uma teoria contratualista ou qualquer tipo de entendimento coletivo a partir do pressuposto do individualismo metodológico e do auto-interesse. Habermas, na sua crítica do modelo hobbesiano, sustenta que não é possível justificar a elaboração de um contrato social a partir do pressuposto de atores auto-interessados sem abandonar o próprio pressuposto. Para que o contrato social seja possível, diz Habermas, duas condições são necessárias. Em primeiro lugar, "as partes teriam de ser capazes de entender o que um relacionamento social baseado no princípio da reciprocidade de fato significa". ${ }^{23}$ Em segundo lugar,

20 Muellek, D. op. cit., p. 52-3. Ênfases minhas.

21 Ibid., p. 54.

22 Buchanan, J. M. The Limits of Liberty: Between Anarchy and Leviathan (Chicago: University of Chicago Press, 1975).

23 Habermas, J. Between Facts and Norms: Contribuitions to a Discourse Theory of Law and Democracy. Cambridge: MIT Press, 1998, p. 91. 
Eles devem ser capazes de assumir a perspectiva social da primeira pessoa do plural, uma perspectiva sempre tacitamente assumida por Hobbes e seus leitores, mas indisponível aos sujeitos no estado da natureza. Com premissas hobbesianas, esses sujeitos não podem assumir justamente o ponto de vista a partir do qual cada um deles poderia inicialmente julgar se a reciprocidade da coerção, que limita o escopo da livre escolha de cada um de acordo com leis gerais, está baseada no igual interesse de todos $e$, assim, pode ser desejado por todos os participantes. ${ }^{24}$

Buchanan e Tullock, em The Calculus of Consent, argumentaram que atores sociais, por não poderem prever em qual situação se encontrarão no futuro, podem assumir uma perspectiva capaz de levar em consideração o interesse de todos os sujeitos auto-interessados, o que criaria as condições para a escolha de normas de interação social que sejam do interesse de todos. ${ }^{25}$ Mueller chama a atenção para a similaridade entre esse argumento e a teoria de justiça de John Rawls, pois esta última está "[...] baseada nos mesmos pressupostos do homem racional $[e]$ egoísta da Escolha Pública e explicitamente evita assumir o altruísmo". ${ }^{26}$ Como se sabe, o modelo contratualista de Rawls postula uma posição original na qual os indivíduos se encontram "atrás de um véu de ignorância", uma condição que os impede de saber qual posição estarão ocupando na sociedade e, com isso, seria possível chegar-se aos critérios para o estabelecimento de uma sociedade justa. ${ }^{27}$ Para Habermas, a posição original limita o escopo de considerações que participantes podem trazer ao processo de deliberação de normas morais.

Rawls impõe uma perspectiva comum às partes na posição original por meio de restrições nas informações disponíveis e assim neutraliza a multiplicidade de perspectivas de interpretação particulares desde o início. A ética do discurso, em contraste, vê o ponto de vista moral como incorporado a uma práxis de argu-

24 Ibid., p. 92.

25 Buchanan, J. M. e Tullock, G. The Calculus of Consent: Logical Foundations of Constitutional Democracy. Ann Harbor: University of Michigan Press, 1965.

26 Mueller, D. C. op. cit., p. 46.

27 Rawls, J. A Theory of Justice. Cambridge: Harvard University Press, 1971. 
mentação intersubjetiva que leva aqueles envolvidos a um alargamento idealizado de suas perspectivas interpretativas. ${ }^{28}$

Como nem Rawls nem Buchanan adotam o conceito de intersubjetividade, mantendo-se limitados pela perspectiva do individualismo metodológico, eles se vêem compelidos a justificar a escolha de normas universais pelo argumento da incerteza em relação ao futuro.

Buchanan afirma que ele e G. Tullock, em The Calculus of Consent, teriam derivado "uma base logicamente consistente para uma estrutura política democrática, que parecia possuir muitas das características da comunidade política [polity] imaginada pelos Founding Fathers".$^{29}$ No entanto, Buchanan faz questão de ressaltar que naquele livro eles não levaram em consideração uma questão que se revelaria importante para a manutenção do acordo constitucional: o problema do controle do crescimento do governo. Essa questão não aparece com clareza até os dois capítulos finais de The Limits of Liberty, quando o tom da argumentação assume um caráter claramente crítico do crescimento do aparato estatal. Nos capítulos anteriores, Buchanan procura justificar em dois planos distintos o acordo que resulta na constituição do Estado.

Em primeiro lugar, existiria o acordo constitucional propriamente dito, contratado por indivíduos auto-interessados com a intenção de instituir um juiz capaz de fiscalizar o respeito aos direitos reconhecidos no entendimento inicial. Esse "juiz" corresponde ao "Estado protetor", que tem a função de garantir os contratos livremente constituídos. Esse acordo contratual, entretanto, não pressupõe uma igualdade entre as partes. "Nós vivemos em uma sociedade de indivíduos, não em uma sociedade de iguais". ${ }^{30}$ Assim como Hobbes e Rawls, Buchanan imagina um acordo "fundador", a partir do qual é estabelecida uma ordem fundamentada no reconhecimento mútuo de direitos. Entretanto, ele não está preocupado em estabelecer critérios para uma justiça distributiva, como está Rawls, nem assume o pressuposto hobbesiano de que, no estado da natureza, "todo homem tem direito a tudo; mes-

28 Habermas, J. "Reconciliation Through the Public Use of Reason". In: The Inclusion of the Other: Studies in Political Theory, Cronin, Ciaran \& GreIfF, Pablo De (eds.) Cambridge: MIT Press, 1998, p. 57.

29 Buchanan, J. M.Limits of Liberty, p. 6.

30 Ibid., p. 11. 
mo ao corpo de outra pessoa". ${ }^{31}$ Para Buchanan, o direito só pode ser concebido sob a ótica da propriedade, pois o "delineamento de direitos de propriedade é, na prática, o instrumento ou o meio pelo qual uma 'pessoa' é inicialmente definida" ${ }^{32}$ Como os homens não são iguais quanto às habilidades que garantem o acesso aos bens da natureza, então os próprios direitos não podem ser igualmente distribuídos. $\mathrm{O}$ acordo inicial no qual os contratantes concordam em depor suas armas - uma vez que o custo individual de proteger os bens que cada um conseguiu se apropriar tornou-se desvantajoso - implica aceitação de uma certa distribuição de direitos, ou melhor, de uma certa distribuição de bens privados. A partir desse momento, o Estado assume a função de proteger os direitos de propriedade de todos. Segundo Buchanan, o caráter do Estado protetor seria "científico": Ao juiz cabe apenas determinar se um contrato foi violado ou não, isto é, emitir uma decisão que implica discriminar o certo do errado.

O Estado tem, entretanto, outra função: a de produzir bens públicos. Segundo Buchanan, o "Estado produtivo é, idealmente, a incorporação de um contrato pós-contitucional entre cidadãos tendo como objetivo o provimento de bens e serviços compartilhados, tal como demandam os cidadãos". ${ }^{33}$ A necessidade de bens públicos é exemplificada pelo dilema do prisioneiro: Há uma ineficiência coletiva se atores auto-interessados agirem por si próprios, quando a cooperação seria mais vantajosa para todos. Dessa forma, para o fornecimento do bem público que beneficiaria a coletividade, seria necessário o compartilhamento dos custos incorridos. Buchanan não se ocupa da questão que preocupou outros teóricos da Escolha Pública, ou seja, que os bens públicos só poderiam ser fornecidos na quantidade e qualidade adequadas se fosse possível chegar-se a uma função utilidade coletiva. Buchanan, apenas enfatiza a sua tese fundamental, isto é, que as intervenções do Estado visando corrigir "falhas de mercado" geram necessaria-mente "falhas de governo" que são o resultado do comportamento auto-interessado dos burocratas.

Dentro das restrições que enfrenta, o burocrata tenta maximizar sua própria utilidade. Ele não é diferente de qualquer um nesse

31 Hobbes, T. Leviathan. London: Penguin Books, 1968, p. 190.

32 Buchanan, J. M. Limits of Liberty, p. 10.

33 Ibid., p. 162. 
aspecto. Dificilmente pode ser considerado capaz de promover algum "interesse público" vagamente definido, a não ser que isso seja consistente com o seu próprio, como ele define esse último. $^{34}$

Um burocrata pode incluir entre seus interesses um desejo vago de contribuir para o bem da coletividade, mas a tendência geral é que seu auto-interesse - ascensão na carreira, prestígio, etc. -, contribua para o crescimento da ineficiência do governo, com o crescimento do aparelho estatal além do que é o desejo dos membros da coletividade. Como veremos adiante, essa tese, desenvolvida principalmente por William Niskanen ${ }^{35}$ e por Anthony Downs, ${ }^{36}$ tornou-se um dos argumento mais conhecidos da public choice e orientou inúmeros os programas de reformas do Estado implementados a partir dos anos 80 . Buchanan adota o argumento do auto-interesse dos burocratas para fundamentar sua proposta de reforma constitucional, que deve ter como meta primordial a contenção do crescimento do Estado:

O propósito das várias seções anteriores foi demonstrar que, mesmo sob as condições mais favoráveis, a operação de processos democráticos pode gerar excessos orçamentários. A democracia pode tornar-se o Leviatã se si mesma, a não ser que limites constitucionais sejam impostos e fiscalizados. Historicamente, o governo tem crescido a taxas que de modo algum podem ser sustentadas por mais tempo. ${ }^{37}$

Apesar do tom de recomendação, Buchanan não se identifica com a idéia de uma public choice normativa. No capítulo final de Limits of Liberty, Buchanan afirma: "Não procurei apresentar em detalhe minhas propostas particulares para uma reforma constitucional; não ofereço uma descrição da 'boa sociedade', nem mesmo em meus

34 Ibid., p. 160.

35 W. Niskanen, Bureaucracy and Representative Government (1971), citado por W. Parsons, Public Policy, p. 310-2.

36 Downs, A. Inside Bureaucracy. Waveland Press, 1994. Obs.: W. Parsons (op. cit.) informa que esse livro, originalmente publicado em 1967, foi resultado de uma pesquisa encomendada pela RAND Coorporation. Assim, temos mais um ponto em comum com alguns dos colaboradores do livro The Policy Sciences, que participaram da atividades da RAND ainda nos anos 50.

37 Buchanan, J. M. Limits of Liberty, p. 161-2. 
próprios termos". ${ }^{38}$ No entanto, por mais que Buchanan resista em reconhecer - e mesmo sem usarmos a definição de Escolha Pública normativa de Mueller -, é evidente que a Teoria da Escolha Pública tem um forte componente normativo. Esse componente normativo não se limita às discussões sobre a alocação interpessoal, como sugere Mueller, mas é imanente à vertente positiva da Escolha Pública, que teve grande influência na formulação de políticas públicas das últimas duas décadas.

Pudemos notar que tanto o diagnóstico como a prescrição de Buchanan não podem escapar de inconsistências teóricas. A primeira, já mencionada, se refere à justificativa de um contrato social por meio dos pressupostos do individualismo metodológico e do auto-interesse. Em Limits of Liberty, Buchanan em diversos momentos parece se render à idéia de que um "contrato" precisa incluir uma outra dimensão de racionalidade além da instrumental. Em dado momento, Buchanan chega a admitir que falta ao seu modelo um conceito de justiça que supere as limitações impostas pela racionalidade instrumental:

Nessa discussão sobre as possíveis mudanças no status quo da distribuição de direitos, [o que demanda] mudanças no contrato constitucional básico, enfatizei as bases econômicas. Não introduzi explicitamente o conceito de justiça, e como ele pode ou não pode orientar as atitudes das pessoas no que se refere ao estabelecimento de, ou mudança na, estrutura. Procurei derivar a estrutura lógica da interação social do auto-interesse maximizador de utilidade de indivíduos e sem recorrer a normas externas. Factual ou historicamente, pode ser necessário que a noção de "justiça social" ou "consciência social" caracterize o pensamento de pelo menos uma parte da população, para que uma sociedade que incorpora razoavelmente a liberdade pessoal possa existir. Não desejo nem apoiar, nem me opor a esse pressuposto. Minha posição é que não desejo me basear na existência de tal atitude neste estágio da análise. ${ }^{39}$

Podemos dizer que falta aos escritos de Buchanan, assim como à teoria da Escolha Pública em geral, um conceito de racionalidade com-

38 Ibid., p. 167.

39 Ibid., p. 80. 
patível com a idéia do entendimento mútuo, ou seja, falta a idéia de racionalidade comunicativa. A teoria da Escolha Pública tem que conviver com o paradoxo de admitir a necessidade um acordo que seja aceito por todos os envolvidos - sintetizado na regra da unanimidade para o fornecimento de bens públicos e na necessidade de normas constitucionais - ao mesmo tempo em que assume o individualismo metodológico e o auto-interesse do Homo oeconomicus como pressupostos.

A teoria da Escolha Pública, após ter percorrido um longo caminho pavimentado com diversos modelos formais, chega ao seu ponto de origem sem ter respondido à sua questão fundamental. Dennis Mueller, que não pode ser acusado de ser injusto com a teoria que abraçou, faz um balanço pouco animador:

Considerando-se os resultados do próprio Arrow, é claro que o policy maker não pode encontrar uma regra de decisão consistente com axiomas normativos óbvios e aceitos por todos. Novos axiomas devem ser encontrados. Mas o quê (quem?) guia o policy maker nessa busca, o economista? A não ser que exista um consenso geral sobre a escolha de postulados de valores pelo policy maker ou economista, o espectro de funções de bemestar social múltiplas reaparece. Mas pode o policy maker, ou o economista, determinar se um consenso existe, e o que é, se não for de alguma maneira expresso literalmente? É significativo que terminemos com essa pergunta. Pois o desafio fundamental enfrentado por uma comunidade é encontrar um consenso ou a saída do dilema do processo decisório na ausência do primeiro. ${ }^{40}$

Assim, mais de trinta anos depois, a Escolha Pública retornou ao "paradoxo da impossibilidade", fechando um círculo. Diante do reconhecimento de que nenhum avanço teórico importante pôde ser realizado pela public choice, seus defensores, aparentemente, optaram por um enfoque menos ambicioso, que se limitou a desenvolver teorias de médio alcance. Esta teorias passaram, então, a orientar estudos empíricos sobre o comporta-mento do Legislativo, partidos políticos, grupos de interesse e burocratas, deixando de lado o problema mais amplo da construção de uma função utilidade social e suas implicações normativas.

40 Mueller, D. C. op. cit., p. 55. 


\section{Da teoria às reformas do Estado}

Pode-se dizer que Mancur Olson, com sua teoria da ação coletiva, inaugurou essa abordagem mais modesta da Escolha Pública. ${ }^{41}$ Ao afirmar que a ação coletiva só é possível para grupos de pequena dimensão, Olson fez com que a formação da vontade política deixasse de ser um problema, mas fez isso tornando-a irrelevante na sua concepção teórica. No entanto, essa seria uma estratégia equivocada, pois, como observou Udehn, "[...] a teoria econômica da ação coletiva de Mancur Olson está aparentemente invalidada pela simples existência da sociedade". ${ }^{42}$ Portanto, dizer que a vontade coletiva só é possível para grupos pequenos - uma tática para manter o pressuposto do auto-interesse -, não é uma solução teórica, mas uma fuga do problema. No entanto, apesar de suas inconsistências, as teorias de médio alcance da Escolha Pública tiveram uma influência decisiva na formulação de políticas públicas nos anos 80 e 90, sendo responsáveis pela construção de uma nova "filosofia" de reforma do Estado, que se tornou conhecida com a denominação de New Public Management - NPM. ${ }^{43}$

O NPM corresponde a um conjunto de concepções sobre o Estado, de preceitos para reduzi-lo e de mecanismos para desenvolver a "eficiência" governamental. ${ }^{44}$ A Escolha Pública é sua principal base teórica, mas há ainda outras abordagens que influenciaram o modelo. Além da Escolha Pública, Jonathan Boston et alii citam a teoria da

41 Olson, M. The Logic of Collective Action: Public Goods and the Theory of Groups (Cambridge: Harvard University Press, 1971).

42 UDEHN, L. op. cit., p. 261.

43 Daqui por diante, utilizaremos a sigla NPM para designar esse modelo. Obs: no Brasil, o modelo do NPM foi denominado "administração gerencial". Ver Bresser-Pereira, L. C. "Gestão do Setor Público: Estratégia e Estrutura para um Novo Estado”. In: Reforma do Estado e Administração Pública Gerencial, Bresser Pereira, L. C. e Spink, P. (Orgs.) Rio de Janeiro: Editora Fundação Getúlio Vargas, 1998.

44 E. Ferlie e co-autores sugerem pelo menos quatro tipos de modelos de NPM: (1) o movimento pela eficiência; (2) a redução do Estado e descentralização; (3) a busca pela excelência; e (4) a orientação para o serviço público. Entretanto, a maior parte da literatura atribui a denominação de NPM apenas aos tipos (1) e (2). Ver Ferlie, E. et al., The New Public Management in Action Oxford University Press, 1996. 
agência, dos custos de transação e o "gerencialismo" 45 com as bases teóricas do NPM, também referido como "o modelo da Nova Zelândia" ${ }^{46}$ Não por acaso, todas as abordagens teóricas relevantes para o NPM adotam o modelo do Homo ceconomicus - auto-interessado e maximizador da utilidade - ou sua versão atenuada, o "Homem Administrativo", que não maximiza, mas apenas "satisfaz" ${ }^{47}$ Não poderemos discutir aqui as particularidades dessas teorias, que juntamente com a Escolha Pública, fundamentaram o NPM. De todo o modo, como os pressupostos que essas teorias adotam são fundamentalmente os mesmos da teoria da Escolha Pública, as observações gerais que fizemos acima sobre a teoria da public choice também se aplicam à elas.

A concepção de Buchanan - ou seja, que o Estado protetor deve se limitar a fiscalizar o cumprimento de contratos -, é particularmente conspícua no modelo do NPM. Como vimos acima, esta tese está fundamentada no pressuposto de que uma vontade coletiva é virtualmente impossível e que toda intervenção do Estado com o fim de mitigar as

45 O "gerencialismo" corresponde à tese de que o setor público deve emular os procedimentos de gestão do setor privado. Entre os procedimentos a serem adotados, estão o pagamento por produtividade, mecanismos de "medição" do desempenho de organizações e funcionários públicos e a autonomia de decisão do gerente. Para alguns autores, como Jonathan Boston et al. (op. cit.), adotam o termo New Public Management apenas para designar o gerencialismo, e não as teorias que o fundamentam, como a teoria Escolha Pública, dos custos de transação e da agência. Para uma avaliação da "reforma gerencial" no Brasil, ver C. Andrews \& A. Kouzmin, "O Discurso da Nova Administração Pública", Lua Nova, 45, p. 97-129, 1990; C. Andrews, "Reformas Administrativas Brasileñas: El Papel (I)real de la Crisis Económica y el Fondo Monetario Internacional", Política y Gestión, v. 3, p. 9-29, 2002; ver também L.C. Bresser Pereira, "A Reforma do Estado dos Anos 90: Lógica e Mecanismos de Controle”, Lua Nova, n. 45, p. 49-95.

46 J. Boston et al., Public Management: The New Zealand Model (Auckland: Oxford University Press, 1996).

47 Herbert Simon cunhou o termo "homem administrativo" para fazer um contraponto ao modelo do Homo œeconomicus. Segundo argumentou, a racionalidade ilimitada da teoria econômica neoclássica - que pressupõe que indivíduos têm acesso a todas as informações necessárias para o processo de decisão -, sendo irrealista, deve ser substituído pelo conceito de "racionalidade limitada", cujo critério de decisão deixa de ser a "maximização função utilidade", ser apenas o da "satisfação". Ver H. Simon, Administrative Behavior: A Study of Decision-Making Processes in Administrative Organizations (New York: Free Press, 1979). 
externalidades negativas de ações privadas gera outro tipo de externalidade, que corresponde ao custo social do rent-seeking. Sob essas premissas, toda intervenção governamental contribui para uma perda de eficiência. Tal avaliação resultou em uma prescrição normativa genérica: deve-se reduzir o Estado a um tamanho mínimo. Naturalmente, o que constituiria esse "mínimo" é fonte de controvérsias e o próprio Buchanan não tentou especificar qual seria dimensão ideal para o Estado americano, apenas insistindo que sua redução seria do interesse geral. Apesar da falta de precisão sobre esse aspecto aparentemente fundamental, reformas administrativas orientadas por esse preceito do NPM foram levadas adiante em diversos países de diferentes níveis de desenvolvimento econômico e social, afetando dos Estados Unidos à Polônia, da Austrália ao Brasil. $\mathrm{O}$ padrão comum às reformas do Estado baseadas no modelo do NPM foi a privatização de serviços públicos. ${ }^{48}$

O crescimento dos gastos públicos na maior parte dos países ocidentais após a Segunda Guerra Mundial atingiu seu apogeu no final dos anos 70. Nesse momento, surgiu uma nova "geração de políticas públicas", que levou os governos a enfatizar a eficiência nos gastos públicos e o controle fiscal do Estado. ${ }^{49}$ Nos anos que se seguiram, principalmente entre 1995 e 2000, quase todos os países membros da Organização para a Cooperação e Desenvolvimento Econômico-OECD diminuíram seus gastos governamentais relativos ao PIB, ainda que essas reduções tenham sido relativamente modestas. ${ }^{50}$ Podemos dizer o momento de ascensão do NPM coincide com o do esgotamento da capacidade do subsistema administrativo em absorver os impactos negativos do subsistema econômico nas sociedades capitalistas. Na ter-

48 Para uma discussão das reformas administrativas no Brasil, ver ANDREWs, C. "Reformas Administrativas Brasileñas: El Papel (I)real de la Crisis Económica y el Fondo Monetario Internacional”, Política y Gestión, v. 3, p. 9-29, 2002.

49 VRIES, M. S. de "Developments in Europe: the Idea of Policy Generations", International Review of Administrative Sciences, 64 (4): 492-510, 1999. Ver também capítulo 1 , p. 13-4.

50 Entre 1985 e 2000 a redução nos gastos governamentais para a região da comunidade européia foi de apenas 6\%; o país que apresentou maior redução nesse mesmo período foi a Suíça, cujos gastos passaram de 60 para $53 \%$ do PIB. OECD (Organization for Economic Co-operation and Development, "Statatistics"; disponível em: http://www.oecd.org/, 2001). 
minologia adotada por Habermas, trata-se, portanto, do momento de eclosão de uma crise de racionalidade. ${ }^{51}$

Aparentemente, a crise de racionalidade e a diminuição do tamanho do Estado em diversos países nas décadas de 80 e 90 contradiz a tese do rent-seeking, pois os protagonistas das reformas foram os políticos e burocratas. Se o auto-interesse leva necessariamente ao crescimento do aparato do Estado, então não há como explicar a redução nos gastos governamentais, por menor que esse seja. Buchanan considerava que só uma reforma constitucional poderia impor limites ao crescimento do Estado. No entanto, uma explicação ao argumento do rent-seeking poderia ser formulada nos seguintes termos: com a política de redução do Estado, políticos e burocratas encontraram uma maneira de "maximizar" o elemento "prestígio" em suas funções utilidade. Uma passagem do livro de Boston et alii poderia ilustrar esse argumento:

Tal tem sido o interesse no modelo da Nova Zelândia que muitas agências governamentais de todo o mundo têm enviado seus executivos e, em alguns casos, consideráveis delegações, a Wellington com o objetivo de explorar em primeira mão a natureza das reformas e avaliar a sua possível aplicação em outros jurisdições. Relatórios detalhados das reformas da Nova Zelândia também têm sido encomendados por diversas agências internacionais e organizações governamentais [...]. E tem havido um fluxo contínuo de convites dirigidos a servidores públicos sêniores $e$ acadêmicos da Nova Zelândia para que expliquem o modelo da Nova Zelândia em conferências internacionais, em revistas acadêmicas e diante de audiências legislativas sobre a reforma do setor público. ${ }^{52}$

Há evidências, porém, de que o entusiasmo pelo modelo do NPM já está se esvaindo. Embora governos tenham investido volumes consideráveis de recursos públicos para a implementação do modelo, pouco se sabe sobre seus resultados concretos. Na Grã-Bretanha, argumentou-se que a falta de vontade política para realizar uma avaliação dos resultados das reformas guiadas pelos princípios do NPM na educação e na saúde refletiria o processo como o modelo foi implementado:

51 Habermas, J. Legitimation Crisis (Boston: Beacon Press, 1975).

52 Boston, J. et al., Public Management: The New Zealand Model. Auckland: Oxford University Press, 1996, p. 3. 
adoção universal seguida de ajustes tópicos, em lugar da experimentação por meio de projetos-piloto seguida de avaliação criteriosa. ${ }^{53}$ Nos países do Terceiro Mundo, as avaliações dos projetos de reforma inspirados no NPM também são escassas. Um estudo comparativo sobre os resultados das reformas gerenciais em países em desenvolvimento concluiu que os ganhos em eficiência - quando existiram - foram provavelmente superados pelo aumento nos custos de transação para realizar as reformas; os avaliadores também notaram que a accountability diminuiu, uma vez que os mecanismos capazes de fornecer a legitimação para a ação do Estado foram insuficientes, tendo como conseqüência o crescimento da desigualdade social. ${ }^{54}$

Pode-se dizer que a crise de racionalidade que se abateu sobre o mundo não foi resultado apenas da crise financeira do Estado; ela teve também um componente ideológico. Os componentes básicos da teoria da Escolha Pública - auto-interesse, troca e individualismo - são abstrações pertinentes ao pressuposto de racionalidade instrumental da Economia, e estão presentes no modelo do NPM. Como mencionamos acima, o conceito de racionalidade adotado pela Escolha Pública não considera a existência da ação social, seja comunicativa ou estratégica. Como Buchanan fez questão de ressaltar, quando a comunidade é numerosa, o indivíduo não age estrategicamente, mas utilitariamente:

Aqui o participante individual não se comporta estrategicamente vis-à-vis seus parceiros; ele trata o comportamento deles como parte de seu ambiente e não considera que sua própria ação pode exercer qualquer influência na de outros que compartilham o

53 Broadbent, J. \& Laughlin, R. "Evaluating the 'New Public Management' Reforms in the UK: A Constitutional Possibility?", Public Administration, 75(3): 488-507, 1997.

54 Manning, N. "The Legacy of the New Public Management in Developing Countries", International Review of Administrative Sciences, 67: 297-312. A fracassada experiência de implementação do Plano de Assistência à Saúde - PAS pela Prefeitura Municipal de São Paulo, também inspirado em preceitos do NPM, reforça essas conclusões: o modelo não aumentou a eficiência dos serviços de saúde - na verdade, encareceu-os significativamente - e também verificou-se a ausência de mecanismos de controle social dos módulos de atendimento. Ver A. Cohn \& P. E. Elias (coord.), O Público e o Privado na Saúde: O PAS em São Paulo (São Paulo: Cortez/Cedec). 
grupo. Nesse contexto, o indivíduo maximiza a sua utilidade abstendo-se de fazer uma contribuição independente para a provisão e o financiamento do bem ou serviço compartilhado." ${ }^{55}$

Dessa maneira, na concepção da Escolha Pública, o próprio indivíduo é considerado um "sistema", tendo todos os demais indivíduos como seu "ambiente". Trata-se de uma concepção que corresponde, na essência, à teoria de sistemas de Luhmann. Habermas é crítico do modelo sistêmico, por considerá-lo um modelo irrealista da sociedade. Luhmann teria assumido que a ruptura entre os sistemas sociais e o mundo-da-vida já teria sido concluída, não havendo nada mais a fazer e, assim, a emancipação tornar-se-ía irrelevante. "Para Adorno" - observa Habermas -, "essa 'sociedade administrada' era uma visão de extremo horror; para Luhmann, ela se tornou um pressuposto trivial" ${ }^{56}$

Cabe salientar que as reformas do Estado segundo o modelo do NPM não se limitaram às privatizações, mas atingiram também as políticas públicas sociais, como as áreas de saúde e educação. Nessa última área foi implementada uma das reforma mais polêmicas do modelo gerencialista. Trata-se da introdução na política educacional de mecanismos de mercado, uma idéia inicialmente apresentada por Milton Friedman ${ }^{57}$ e adotada em larga escala na Grã-Bretanha durante o governo da ex-primeira-ministra Margareth Tatcher. Nesse modelo de reforma educacional, o governo deixa de ser o fornecedor de serviços educacionais, limitando-se a distribuir vouchers ("vales-educação") para pais de crianças e jovens em idade escolar, que são, então, trocados por serviços educacionais oferecidos por instituições privadas. O pressuposto básico dessa proposta é que, devido à competição entre fornecedores, mecanismos de mercado melhorarão a qualidade e a eficiência dos serviços educacionais. A proposta parece sedutora, mas tem implicações que não devem ser escamoteadas. Quando uma política educacional baseada no sistema dos vouchers é adotada, outras alternativas de políticas educacionais são descartadas. Assim, os pais de alunos não têm outra opção a não ser comportarem-se como a teoria da reforma espera que se comportem. Nesse caso, a política induz à

55 Buchanan, J. M. Limits of Liberty, p. 37.

56 HABERMAS, J. TCA, v. 2, p. 312.

57 Friedman, M. "Free Market in Education", Public Interest, 3: 107 (1966). 
"maximização" dos vouchers, ou seja, seus portadores são incentivados a trocá-los pela melhor educação disponível no mercado. Desde que, é claro, os pais tenham informações sobre a qualidade as escolas, um pré-requisto que mesmo economistas mais conservadores admitem que favorece as famílias mais ricas em detrimento das mais pobres. Os pais de alunos também serão indiretamente orientados a deixar de lado outros comportamentos - como uma ativa participação nas escolas - uma vez que essas alternativas não são privilegiadas na estrutura da política. Talvez não seja mera coincidência que a Grã-Bretanha, onde foi implementada uma reforma educacional baseada no modelo do NPM no final dos anos $80,{ }^{58}$ seja atualmente o país com os maiores índices de delinqüência juvenil de toda Europa. O relato da revista liberal inglesa The Economist é ilustrativo:

Na década passada, expulsões de escolas e a incidência de doenças sexualmente transmissíveis explodiram. A proporção de meninos de 14-17 anos que admitem ter violado a lei aumentou 14\% entre 1993 e 1999; as meninas estão cada vez mais compartilhando a diversão do crime violento. Jovens não se limitam mais a crimes contra a propriedade como antes. E cometem mais violência contra si mesmos: a taxa de suicídio entre ingleses do sexo masculino entre 15 e 24 anos mais do que dobrou nos últimos 30 anos. ${ }^{59}$

O articulista admite que não é possível atribuir essa situação somente ao contexto de declínio econômico, uma vez que os problemas sociais envolvendo os jovens não se restringem aos filhos de trabalhadores desempregados, mas afetam todas as classes sociais. Mais um

58 A reforma da educação foi introduzida na Grã Bretanha em 1988, por meio do Education Reform Act. Embora não tenha adotado o modelo mais radical dos vouchers - no qual todas as escolas são entidades privadas -, a reforma britânica introduziu o mecanismo de mercado no sistema de escolas públicas. Basicamente, os pais de crianças e jovens em idade escolar passaram a poder escolher em qual escola pública matricular seus filhos. O governo, por sua vez, aloca recursos orçamentários para escolas com maior número de alunos matriculados. Há portanto, um incentivo à criação de escolas com grande número de alunos, enquanto as escolas com pouco alunos tendem a fechar as portas por falta de recursos financeiros. Ver S. Gorard \& J. Fitz, "Markets and Stratification: A View from England and Wales", Education Policy, 14(3): 405-28, 2000.

59 The Economist, "The Naughty Boy of Europe", edição de 14 de fevereiro de 2002. Disponível no site: http://www.economist.com/. 
sinal de que Habermas pode estar certo. Como ele enfatizou, nas sociedades capitalistas desenvolvidas, as patologias sociais não são mais específicas de uma classe, mas afetam a sociedade como um todo. ${ }^{60}$ Entretanto, cabe lembrar que Habermas tomou como foco de sua teoria as sociedades de Bem-Estar Social antes de adotarem as reformas liberais segundo os preceitos do NPM. Sua preocupação estava voltada para a burocratização promovida pelo Estado de Bem-Estar Social, especialmente a crescente "juridificação" ${ }^{11}$ das relações entre as organizações estatais e seus clientes. Podemos especular que as reformas do NPM, portanto, tenham colaborado para aumentar o risco de ocorrência de patologias sociais induzidas pelo razão funcionalista do sistema administrativo.

O declínio do modelo do NPM no final dos anos 90 pode ser compreendido como uma crise de legitimidade. Como Habermas argumentou, enquanto a crise de racionalidade corresponde ao momento no qual o sistema administrativo não pode mais neutralizar os efeitos do sistema econômico, devido à crise financeira do Estado, a crise de legitimidade é o momento no qual os efeitos patológicos de um sistema econômico liberado das interferências do Estado ressurgem com força, desestabilizando as formas de vida da sociedade. ${ }^{62}$ No final dos anos 90, o agravamento das patologias sociais que se seguiu à onda de reformas do NPM parece corresponder à uma crise de legitimidade especialmente intensa. O "encolhimento" de Estado em esferas nas quais já havia sido estabelecido um espaço de integração social - como as escolas públicas - pode ter sido um elemento agravante da crise.

Podemos concluir que, ao contrário da maior parte das teorias políticas contemporâneas, a teoria da Escolha Pública teve conseqüências bastante concretas na vida de milhões de cidadãos no mundo todo. A questão que se coloca agora é se o este início do século XXI apresentará as condições sociais e políticas que favoreçam o florescimento de uma teoria social crítica que também tenha conseqüências práticas. A

60 Habermas, J. TCA, v. 2.

61 O termo "jutidificação" usado por Habermas refere-se à padronização aplicada às relações entre cidadãos e o Estado por meio da regulamentação legal, que impõe uma padronização na interpretação de situações sociais que deveriam estar sendo tratadas de acordo com suas espeficidades.

62 Habermas, J. Legitimation Crisis, op. cit. 
expectativa é que em vez de termos uma teoria que acabe induzindo à emergência de patologias sociais, tenhamos uma que aponte os caminhos para a emancipação. Aparentemente, essa é uma ambição difícil de ser contemplada. No entanto, como a trajetória da teoria da Escolha Pública nos mostrou, teorias desenvolvidas entre as paredes da academia, podem, se as condições forem propícias, ganhar "corações e mentes" e ganhar espaço em terrenos mais amplos. 